\title{
ANNOUNCEMENTS
}

\section{Change in Editorship}

Robert C. Bolles will assume editorship of Animal Learning \& Behavior in 1981. After March 31, 1980, please send manuscripts to him at: Department of Psychology, University of Washington, Seattle, Washington 98195.

\section{XVIIth International Ethological Conference \\ September 1-9, 1981 \\ Oxford, England}

The U.S. Committee of the International Ethological Conference wishes to broaden the base of participation in the biannual meeting and, hence, is inviting applications from psychologists whose interests are highly relevant to ethology. U.S. participation is restricted to 110 delegates. Potential delegates are voted on by a committee of nine persons. Those receiving the highest ranking receive invitations, irrespective of previous participation. (As many as 400-500 persons are expected to compete for the 110 invitations.) Those who submit applications should be prepared to pay their complete travel and lodging expenses. Of the 110 delegates from the U.S.A., $25 \%$ will be graduate students and recent postdocs ( $\leqslant 3$ years postdoctoral experience).

To be placed on the mailing list for an application form, at this time merely send your name and address to

\author{
Dr. Marc Bekoff \\ Department of EPO Biology \\ University of Colorado \\ Boulder, Colorado 80309
}

Application forms and full instructions will be mailed in due course. 